University of Wollongong

Research Online

Faculty of Social Sciences - Papers (Archive) Faculty of Arts, Social Sciences \& Humanities

2016

Women drinking alcohol: assembling a perspective from a Victorian

country town, Australia

Gordon R. Waitt

University of Wollongong, gwaitt@uow.edu.au

Susannah Clement

University of Wollongong, sc527@uowmail.edu.au

Follow this and additional works at: https://ro.uow.edu.au/sspapers

Part of the Education Commons, and the Social and Behavioral Sciences Commons

Research Online is the open access institutional repository for the University of Wollongong. For further information contact the UOW Library: research-pubs@uow.edu.au 


\title{
Women drinking alcohol: assembling a perspective from a Victorian country town, Australia
}

\author{
Abstract \\ Gender is a key lens for interpreting meanings and practices of drinking. In response to the overwhelming \\ amount of social and medical alcohol studies that focus on what extent people conform to norms of \\ healthy drinking, this article extends critical feminist geographical engagement with assemblage thinking \\ to explore how the technologies of biopower covertly materialised as bodily habits may be preserved and \\ challenged. We suggest an embodied engagement with alcohol to help think through the gendered \\ practices and spatial imaginaries of rural drinking life. Our account draws on interviews with women of \\ different cohort generations with Anglo-Celtic ancestry living in a country town in Victoria, Australia. Three \\ vignettes based around emergent themes of maternal, domicile and socialising bodies help shed light on \\ the contradictory ways gender is lived through the dynamics of alcohol consumption which help \\ constitute everyday life in a country town.
}

\section{Keywords}

perspective, women, drinking, alcohol, assembling, australia, town, victorian, country

\section{Disciplines}

Education | Social and Behavioral Sciences

\section{Publication Details}

Waitt, G. R. \& Clement, S. (2016). Women drinking alcohol: assembling a perspective from a Victorian country town, Australia. Gender, Place and Culture: a journal of feminist geography, 23 (8), 1121-1134. 
Women drinking alcohol: assembling a perspective from a Victorian country town, Australia

Gordon Waitt* and Susannah Clement

Gordon Waitt

Department of Geography and Sustainable Communities, University of Wollongong

Faculty of Social Science, Department of Geography and Sustainable Communities, University of Wollongong, NSW 2522

Email: gwaitt@uow.edu.au

Susannah Clement

Department of Geography and Sustainable Communities, University of Wollongong

Faculty of Social Science, Department of Geography and Sustainable Communities, University of Wollongong, NSW 2522

Email: sc527@uowmail.edu.au

Word count: 9075 (no figs)

Cn: yes

Ackn: yes 


\title{
Women drinking alcohol: assembling a perspective from a Victorian country town, Australia
}

\begin{abstract}
Gender is a key lens for interpreting meanings and practices of drinking. In response to the overwhelming amount of social and medical alcohol studies that focus on what extent people conform to norms of healthy drinking, this article extends critical feminist geographical engagement with assemblage thinking to explore how the technologies of biopower covertly materialised as bodily habits may be preserved and challenged. We suggest an embodied engagement with alcohol to help think through the gendered practices and spatial imaginaries of rural drinking life. Our account draws on interviews with women of different cohort generations with Anglo-Celtic ancestry living in a country town in Victoria, Australia. Three vignettes based around emergent themes of maternal, domicile and socialising bodies help shed light on the contradictory ways gender is lived through the dynamics of alcohol consumption which help constitute everyday life in a country town.
\end{abstract}

Keywords: embodiment; collaborative knowledge; generational; health; self-care

\section{Introduction}

Public health data shows that alcohol consumption is a gendered, aged and spatially differentiated activity in Australia. A recent Australian Institute of Health and Welfare survey illustrated that men, particularly those aged between 18 and 29, living in locations categorised as 'rural' drink on more occasions and consume alcohol in higher quantities compared to their metropolitan counterparts (AIHW 2011). Likewise, men living in locations classified as 'rural' are more likely than women to experience alcohol-related harm, regardless of where they live (AIHW 2011). Such gendered spatial patterns, practices and medical risks related to alcohol consumption are a focus of political concern and interest in the public health literature (Miller et al. 2010). Yet, as Miller et al. (2010) laments, such studies often fail to investigate the 'mechanisms' between drinking health inequalities, gender and place. We argue that recent theorising in human geography, which conceives bodies as composite entities within assemblages, has much to offer in comprehending gendered rural 
drinking patterns. Assemblage thinking generates new questions that emphasise the role of alcohol in modulating the continuous making and remaking of rural places and gendered bodies by paying attention to both material and expressive forces. This article explores the role of alcohol in forging gender differences by exploring how women accomplish and hold together everyday life in a country town with a population of 1,400 in Victoria, Australia. Most existing social science literature on alcohol consumption focuses on the forces shaping and reshaping drinking and drunkenness within inner-city nightlife (see Bøhling 2015; MacLean and Moore 2014; Shaw 2014). Our focus on women in the context of a country town offers an understanding of how technologies of power can be widely exercised and reproduced by encoding them in somatic norms that, performed as bodily habits, become taken for granted. In other words, the 'proper' country woman, who is assumed to stay sober and care for husbands and children, is an example of the embodiment of norms that work to reproduce women's social disempowerment and help explain women's lower experience of alcohol-related harm. However, just as ideologies of patriarchal domination impose repressive identities on women, these technologies of power can be questioned and unsettled by emotional and affective relationships that exist and play out within the context of everyday life.

The article builds on and contributes to critical scholarship on geographies of alcohol that, echoing the words of Wilton and Moreno (2012, p.107), engage with drinking and drunkenness through a de-centring of medical, criminal, and moralistic models (Jayne et al. 2006, 2011; Sweeney 2014). Our argument is that gendered bodies are an outcome of an 'object-target of' and 'condition for' contemporary forms of biopower based around forms of intervention that aim to optimise the sober body against the threat of intoxication. Drawing on Foucault (1978), a range of work contends that the technology of biopower has arisen within the advent of large data sets indicating trends of alcohol-related medical and social 
'risks', together with political rationalities of capitalism entailing the individualisation of risk and the formation of neo-liberal subjects (Day et al. 2004). This governing of the biological self has resulted in a conglomeration of new policies on alcohol consumption that focus on understanding and making 'wise choices' about the medical risks of drinking to excess. A new pathological figure emerges: the individual or group that makes the wrong drinking choice and is forced to take individual responsibility. As a result, health, and its pursuit by the individual, is increasingly central to the ideal of citizenship. Examples of policies that encourage us to become 'good citizens' by self-care of the biological body through monitoring alcohol consumption span from the promotion of recommended alcohol units and 2am 'lock-outs' operating in some Australian urban areas, to the implementation of Liquor Accords that ban the sale of alcohol to those previously charged with disorderly drunken behaviour. The health risks associated with drinking are conceived as manageable if people actively engage in the adoption of appropriate self-care measures and timing of alcohol consumption aimed at deterring violent and disorderly behaviour (NHMRC 2011). Translated into the Foucauldian concept of biopolitics, defined as the care of life, these policies illustrate that not only our conduct (drunkenness) but also our corporeality (organs) are open to discipline. However, do these accounts fully exhaust the relationship between drinking and biomedical bodies? Missing from these accounts that focus on how bodies have become the 'object-target' for specific technologies of power is any understanding of how individuals render their bodies to themselves, making judgements about them and acting upon them. The individual who thinks about their body through how alcohol transforms biological processes and 'takes responsibility for their health' may also be the person who thinks about their body in the 'to' and 'fro' of everyday life, whether through the effects of caring for others or socialising. 
To conceive how bodies have become the 'object-target of' and 'condition for' biopower we build on geographical studies that draw on post-structuralist feminist ideas that privilege drinking bodies in a dynamic and open way. Drawing on assemblage thinking, we bring to the fore the 'somatic self' that puts the body's experience as a locus of selfknowledge and self-care and argue that alcohol mediates the relationship between bodies, place, gender and risk. We envisage alcohol as a material and expressive force that assembles bodies and spaces. Rather than working with pre-configured social categories of gender that are expressed through drinking, we are alive receptive to ideas that it is through drinking that people get to know themselves and relationships with others. Building from these ideas we conceptualise drinking as way of experiencing, creating and comprehending gendered relationships under particular circumstances. This requires us to think critically about drinking the world into existence as ways of being and becoming, while suggesting a mutuality between drinking, bodies, affect, emotion and place. Our suggestion in this article is that insights into gendered rural drinking patterns and practices are offered by considering the contingencies of place. For us that means comprehending the compromises and contradictions of how different individuals come to know themselves, others and places through the choice to consume alcohol, or not.

\section{Theoretical framework}

Interest in alcohol is gathering momentum across geography and cognate disciplines in the social sciences. One important strand within this growing body of work is underpinned by theoretical frameworks that demonstrate the gendered sociocultural meanings of drinking and intoxication. Intersecting themes of risk and respectability emerge in the social science literature that explores the moral, medical, political and social dimensions of women who drink. For example, Waterson (1996), Ettore (1997) and Fox et al. (2009) discuss the historical weight of ideas that align white middle-class feminine respectability, motherhood, 
maternal love, temperance, virtue and bodily control. Likewise, Day et al. (2004) and Jackson and Tinkler (2007) discuss the emergence of the figure of the 'ladette' as a symbol of a degraded femininity in media discourses which mimic the competitive sociability of masculine drinking bodies. Conversely, McRobbie (2009) argues that the fun-loving ladette retains credibility so long as her performance of masculinity does not challenge the realms of heteropatriarchy. Furthermore, Fox et al. (2009) discusses how the drinking maternal body is conceived as a site of heightened biomedical and social concern through the legal construction of the foetus as a person with rights and the medical construction of the foetus as a patient. Important insights for this article are generated by the ways in which the intoxicated body is shaped as an 'object-target' for power and employed as an instrument to reflect and sustain gendered social difference through discourses of respectability, femininity and motherhood, cross-cut by age, class and ethnicity (Jayne et al. 2011).

Another important strand of literature is the work of geographers that builds upon theoretical frameworks that deploy Deleuze and Guattari’s concept of assemblage to emphasise the aesthetic quality of the body’s ‘inner’ experience (Bøhling 2015; Jayne et al. 2006, 2010, 2011, 2012; Leyshon 2008; MacLean and Moore 2014; Shaw 2014). Assemblage thinking underscores the embodied, emotional and affective experiences of drunkenness within particular contexts and troubles conventional understandings of drunkenness as attributable solely to bio-chemical qualities of alcohol (Race 2009). For example, Bøhling’s (2015) and MacLean and Moore’s (2014) research findings relating to play and young people's experience of drunkenness as part of the nightlife in Copenhagen, Denmark and Melbourne, Australia, respectively, point to the importance of the dynamics of bodies, spaces, emotions and affects attributable to the alcohol. Likewise, Jayne and Valentine (2014) argue that the playful politics of intoxication are always precarious and contingent on 
embodied experiences, identities, states and non-human materialities (e.g. lighting, drinks, seating and music).

One focus of assemblage thinking is exploring how gendered drinking subjects emerge and are part of the conditions for biopower through the encounters between discourses, bodies, space, affects and emotions. For example, Waitt et al.’s (2011) investigation of young women's alcohol-related pleasures points to the acquisition of new corporeal skills and speech acts to help transform their gendered subjective experience and become 'other' in public spaces of a regional Australian city. In each case, participants described how intoxication and associated performativities of drunkenness enabled different expressions of the gendered self to be enacted that facilitated legitimacy within their friendship circles through conventional masculine bodily proficiencies such as drinking excessively, fighting, sexual assertiveness and defecating in the street. As Race (2009) argues, the focus on drinking play, practices and performativities is vital because the pleasures of using drugs are related to how they make new bodily and social existence possible by losing oneself in the present. Likewise, Waitt and De Jong (2014) explore how the embodied knowledge of alcohol helps shape the gendered times, spaces and subjectivities that constitute the weekend in an Australian country town. Crucially for this article, they argue that the sensual experience of both alcohol tastes and contents may either assert or subvert bodily, spatial, social, spatial or temporal boundaries that evoke a world in which new relations, subjectivities and commonalities may be created.

In this article we build on post-structural feminist geographers to conceive of gendered bodies and space as co-constituted within alcohol-fused assemblages (Jayne et al. 2010; Waitt et al. 2011; Tan 2013). In order to do this we turn to the Deleuzian-inspired writing of post-humanist feminist scholars including Probyn (2005) and Grosz (1994) whose work suggests the need for an account of alcohol and drinking more alert to bodies and 
spaces as composite rather than bounded entities. Such an account of alcohol undermines the ontological conventions that inform most public health and social science thinking that is reliant on the distinction between biology/technology, inside/outside and subject/object. What interests us is how a posthuman account of alcohol offers possibilities to revisit the prescriptive social determinants of health model (Fox 2012).

A post-structuralist, geographical and feminist approach that conceptualises drinking alcohol through an assemblage of material (bodies, objects, technologies and spaces) and expressive forces (signs, meanings, affects, emotions and desires) suggests the need to focus on the bodies, space, affects and emotions in each drinking event. Brought to the fore in assemblage thinking are the particularities of alcohol as it is lived and made meaningful in a particular context. Gender can no longer be thought along structuralist approaches as a force 'out there' and imposed 'from above' that is a stable homogenous entity. Instead, the practices and experiences that comprise gender are conceptualised as assembled within the flows or connections that coproduce bodies, spaces and affective/emotions that comprise the unfolding contexts of everyday life. The embodied knowledge of drinking is always contingent on the forces emerging from the instance of consumption, and is always shaped by power that is employed to differentiate bodies/spaces and sustain social forces along the lines of sex, gender, class, ethnicity, ability, beauty and health. Alcohol is conceived as both shaped by and harnessed for the making of gendered bodies/spaces. It is through the spatial and temporal experiences of alcohol use, which are socially, culturally and physiologically registered, that bodies learn to be affected by and affect others, and the contextual force of gender comes to 'be present' in the event. It is therefore possible to think of gender fashioned within an assemblage of situated body sizes, shapes, gestures, practices; in combination with affective and emotional responses to the ideas, smells, textures, tastes and sights of alcohol that help configure and reconfigure spatial, social and moral orders. 


\section{Methods}

This study was conducted in May and June 2013 in Bellevue: an Australian country town located in the foothills of the Snowy Mountains, Victoria, with a population of approximately 1,400 people (ABS 2012). Bellevue is in excess of 100 kilometres by road to the closest regional centre and over 300 kilometres by road to a state capital. There is no rail access and the main road into the town was only sealed in the 1990s. Bellevue is representative of inland service towns that are deeply embedded in the white cultural histories and economies of the primary resource sector. Like many Australian country towns, the cultural norms of alcohol supply and gender are part of the historical legacy of White Australia. Bellevue's two pubs facilitate drinking cultures that are integral to reaffirming hegemonic 'football' masculinities (see van Campenhoot and van Hoven 2014). Alongside the pubs, Bellevue hosts a range of hospitality spaces that are more inclusive of women, including cafés, a cinema, a hybrid barrestaurant and a country club. In Bellevue, the moral panic around drunken bodies has resulted in new forms of governance. In 2008 a Liquor Accord was implemented to ban anyone involved in alcohol-fuelled violence from entering a licensed venue or purchasing alcohol within the town (Liquor Accord 2012).

Cognisant of the discursive construction between alcohol and woman, participants were invited to participate in a project entitled ‘Going Out and Staying In: Women’s Experiences of Leisure Time in Bellevue'. Participants were mainly recruited through placing posters in businesses, the Visitor Information Centre and public library. The 17 women who gave their consent shared commonalities underpinned by rural heterosexualities that give primacy to marriage, reproduction and domestic labour. All participants were of Anglo-Celtic descent. For all our participants mothering was an essential part of their identity. The sample of women varied by age, employment histories, marital status, drinking histories and whether they considered themselves 'local'. Participants' ages ranged from 22 to 78 years. Three 
participants were aged 18 to 34. In this younger cohort generation all participants had children aged five or less and one was pregnant. Seven participants were aged between 35 and 54. Of this mid-generation cohort, two participants had children under the age of 10, three participants had teenage children and two had adult children. Seven participants were aged over 60 and comprised our mature cohort generation. Five of these women were grandmothers. In terms of paid employment, seven worked part-time and three worked fulltime. Four conducted the office work on-farm or at home. Five volunteered their time to community organisations and five were retired. One participant was unemployed and looking for work. Five participants thought of themselves as 'local', tracing a family legacy of three or more generations born in the town. For all other participants, migration to Bellevue was always narrated as a practice they understood as being supportive to their husband's career and involved taking up the majority of domestic tasks. Only one of our participants never drank alcohol. Three narrated drinking only when celebrating a birthday or wedding, and 11 reserved their drinking to help define the weekend, drinking more than two glasses of wine on special occasions. Two participants drank alcohol regularly - at least one glass of wine, beer or spirits each weekday. To maintain participant anonymity both the country town and participants were given a pseudonym and we have not included images.

Mindful of the theoretical framework, participants were asked to participate in a drinking ethnography that combined an alcohol biography with photo-elicitation. Interviews were conducted by one of us, normally in a café. To understand why people consume alcohol, or not, as part of everyday life we invited participants to explore four themes: (1) Tell me about yourself; (2) Going out; (3) Staying in; and (4) Drunkenness and problem drinking. One of us shared narratives of our drinking experiences to help participants generate narratives about 'going out' in Bellevue. Nine participants accepted our invitation to take photographs and meet to discuss, reflect and re-enact the decisions they engage in. The 
photographs revealed their routine actions and movements as drinking is bundled into sets of activities such as unwinding at the end of the day, celebrating birthdays, the 'girls night out', catching up with friends and dinner parties. The photographs permitted a deeper reflexivity than semi-structured interviews by offering participants opportunities to show us drinking activities they or others engaged in to make places 'feel' right. The photographs do not ‘capture’ sensory experiences. However, they allow participants to include in their narratives verbal descriptions and embodied representations (for example facial expressions and gestures) of their drinking bodily sensations, emotions and moods implicated by drinking in different places. Interviews were transcribed verbatim, varying in length from around 30 to 80 minutes’ duration. Using ethnographic narrative analysis the transcripts were systematically coded under a number of thematic categories including family, friends, home, work, guilt, horror, happy, drunkenness and belonging. Three interrelated key themes emerged that were expressed through and with alcohol: maternal, domicile and socialising bodies. Following the lead of Jayne et al. (2011), what follows are three vignettes to learn about gender not as a pre-existing thing, but as expressive of the connections between spaces, bodies, affects and emotions. Vignettes provide a platform for us to learn more about the embodied elements in making sense of individual drinking experiences in different places. These vignettes were selected because they provide individual insights within and between cohort generations into how gender was expressed through and with alcohol, and how connections are made and lost in the emergent subjectivities of mothers and wives in particular contexts.

\section{Maternal bodies}

For the younger women we interviewed, aged 18 to 34, their practices as mothers were central to their subjectivities and offers example of an 'affective condition’ bound up with the biopolitics of alcohol. As a result, many often spoke about the visceral guilt of drinking 
against the constant juggling of their sole responsibilities of doing domestic labour, including childcare. For example, Kayla is a 22-year-old mother who is engaged to the father of her two children. Kayla worked part-time at an employment agency, but, like many of our participants, had recently decided to leave paid work to become primary carer for her children. Kayla's drinking history is shaped by growing up in a regional Australian centre in the early 2000s with limited leisure opportunities for teenagers. She was introduced to alcohol at a young age by her parents, who then later supplied alcohol for underage consumption at house parties. These instances of binge drinking produced affective relationships enabling her to compete with male counterparts and show leadership amongst her female friends.

Kayla: So when I started at 13 it was to get drunk, that was the point of it, not to taste it, like everybody bring money, we'll buy the slabs let's just get wasted... I threw fake birthday parties so my friend's parents would let them come and get drunk... Yeah looking back now, I wish I would have been a bit more responsible, but it was going to happen no matter who it was. Unfortunately it was me. I got the majority of my high school friends drunk for the first time.

Echoing findings by Griffin et al. (2009), Leyshon (2008) and Jayne et al. (2011), Kayla described the strong peer pressure to drink and the motivations of drinking to become drunk. Kayla described being and becoming 'wasted' as inevitable, given she considered alcohol essential to being part of the crowd and having fun through losing inhibitions. For Kayla, drinking as a teenager was like riding was for Probyn (1996, p.36): a 'wild passion ... the desire for being at the very edge of control'. Kayla illustrates how in Deleuzian terms the practice of drinking may be conceived of as changing bodily capacities for affecting and being affected by producing 'intensities', forces and sensations that connect bodies to other human bodies to ideas that transform their sense of self and regional Australia. 
Kayla continued to binge drink most weekends until she became pregnant at 17 years of age. As feminist analyses of the relationship between medical discourses, alcohol and pregnancy argues, pregnant bodies tend to be viewed as a cultural site that reinscribes gendered and classed norms regarding motherhood (Fox et al. 2009). Today, her drinking practices may be understood in terms of how she negotiates various dominant classed, gendered and scientific discourses of a 'good' mother, friend and partner. Kayla explained that drinking to become drunk is now limited to a 'girl's night out' at the pub that occurs irregularly - three to four times a year. The limited opportunities for a 'girl's night out' gives rise to heightened affective intensities. Kayla treasures the sociality of a 'girl's night out' and enjoys pushing the boundaries of normalcy in the conventionally male-orientated pub.

\footnotetext{
Kayla: ... I always just figure I don’t go out much so I like to dress up. I always go out in heels to the pub. I would never wear flats out, and I get a lot of compliments on my shoes, 'cause they are glittery, so everyone notices them. So I, umm, like to put in a little bit of effort, but most of the girls don't bother; sort of wear what they wore to footy, but if us girls go out and we plan to go out we'll dress up. Even if we go out to dinner, we'll dress up. We just say yeah we don't get to go out much so we might as well just enjoy it while we can.
}

In this case by ascribing to elements of what Connell (1987, p.183) called 'emphasised femininity’, Kayla disrupts the line between respectable and disreputable rural femininities, safety and known risks. Kayla's quotation shows how affective relations and capacities of a girl's night out are understood as a rupture to everyday life. The intense affective relationships of a girls' night out are heightened because they only occur three or four times a year. The embodied experience of alcohol in the context of a 'girl's night out' illustrates the empowering pleasures of alcohol to help overcome gendered limits.

Kayla goes onto explain how, within her friendship network, ideas of being 'alternative' are taken for granted and yet constantly challenged by other women in the pub: 
Kayla: .... sometimes I notice one girl like [rolls eyes] looking at you funny. And, sort of they get the wrong impression. They just think you're, you know, a bit of a tart or whatever. But most of the time I'm out with Jason [her fiancé] and so it probably doesn't look too weird to the majority of people and anyone who knows me know, knows the fact that I do dress up.

As Skeggs (2002) argued, women’s physical appearance is a site of regulation and surveillance that may be simultaneously a site of pleasure and anxiety. Kayla reveals the strongly gendered and moral codes that regulate relationships and behaviours in rural pubs. Single women who present their bodies in ways to be read as feminine and 'sexy' in the Bellevue pub could be understood as representative of performing a devalued femininity based on promiscuity. Kayla reveals how women exercise surveillance over other women’s bodies and how marriage operates a symbol of normalcy. In Kayla's words, 'most of the time I'm out with Jason and so it probably doesn't look too weird'. As Leyshon (2008) and Donkersloot (2012) argued, women are often disempowered within rural communities through moral-coded sanctions that regulate the dressing and drinking of bodies in pubs.

At the same time, dressing up and going out to get drunk with girlfriends also made Kayla reflect on her desire of being and becoming a 'good' mother. The risky pleasures of alcohol consumption are understood for Kayla as incompatible with gendered constructions of care, motherhood and domestic labour. As Kayla tells:

Kayla: ... like if we [the girls] stay out I get a lot of mother guilt. Like oh: 'Now I'm going to be too sick tomorrow', to, you know, do my best, and get up and cook dinner early. And whilst dads aren't like that, it doesn't matter if they are hung over ...

In the mix of how gender is lived through drinking bodies, across our transcripts guilt is experienced by younger women in the process of being and becoming mothers. Kayla articulates the guilt of staying out late and raising children with a hangover. Guilt leads to an articulation of normative constructions of parenting. As Longhurst (2008) argues, mothers are 
expected to be 'good', warm, caring and selfless. In addition, Day et al. (2004) would add that 'good' mothers are also expected to be sober and stay at home. Hence, as Longhurst et al. (2012, p. 296) argues, 'all mothers are likely to feel guilt at some point and in some contexts given the way in which mothering is constructed within normative frameworks'. In this case, Kayla's guilt is associated with the experience of a hangover preventing her from juggling the multiple tasks that enable her to care properly for her children. As Tomkins et al. (1995, p.133) explain, guilt 'is felt as an inner torment, a sickness of the soul'. Contrary to Probyn's (2005, p. 45) argument, this affective and emotional guilt from drinking is not easily 'smoothed away by an act of reparation'. Instead, this guilt is ingrained in and through the body. In Longurst et al.'s (2012, p. 299) words, maternal guilt reveals 'mothers’ dreams, hopes, worries, concerns, values and aspirations not only for themselves but also for their children'. The maternal guilt of drinking makes Kayla reflect on the time taken away from caring for her children:

Kayla: ... Yeah or if it's a Saturday, they [dads] just sleep in. Dads are just allowed to go out and do it [get drunk] and have no expectations. No one is disappointed in them. They aren’t guilty or anything. Like mums put a lot of pressure on themselves, even when they have fun, to you know be the parent first, whilst dads are parents second.

Kayla's experience of guilt from drinking to excess is shaped by normative ideas of genderdefined childcare responsibilities within heterosexual relationships. This guilt is relational and about hegemonic constructions of the 'good' mother. In all cases, the gendering of childcare and the lack of men's contribution to domestic work operated as moral references that sanctions excessive drinking of fathers. In Kayla's words, 'No-one is disappointed in them'. Seemingly, in the wider rural community paternal drinking is sanctioned within marriage because of the assumed gendered division of domestic labour and inequalities among men and women in terms of childcare responsibilities and leisure. 


\section{Domicile bodies}

The second example is illustrative of how gendered biopolitical techniques related to in-home drinking activities shape the capacity of domicile bodies to affect and be affected. All participants spoke about negotiating parental and societal expectations regarding drinking at home. This illustration is drawn from one of our mid-generation participants (aged 35-54), Jessica, who is a widowed 50-year-old mother of three adult sons and lives on a small property. Jessica expressed a preference to abstain from drinking and described a 'heavy night' of drinking for her as four glasses of red wine.

Born in a country town but raised in suburban Melbourne, Jessica moved to Bellevue when she married a farmer in the 1980s. In the interviews, Jessica explained how when growing up drinking alcohol was against family 'rules'. Jessica stressed how this ban was imposed by her mother in relationship to a narrative of family crisis and the shame attached to the figures of an alcoholic grandfather and father. Like Kayla’s narrative, Jessica drew attention to underage drinking, however done without parents' knowledge. At the age of 14, she and two friends stole an older sister's identification card, bought two bottles of cheap spirits and drank them in a Melbourne park. In Jessica’s words her 'mum had no idea'. However, unlike Kayla, Jessica did not describe deliberately going out to become drunk or peer pressure to drink to excess. Instead, the affective elements of alcohol helped her consolidate friendship networks within marginal public spaces. At 18 years of age, Jessica stressed that the male-orientated pub still held limited possibilities in affirming her gender as a young woman.

Jessica: And I know when I was 18, ummm... you, it, just I couldn't go to the pub by myself as an 18 year old, I didn’t know anybody. You can’t just walk in there as a girl to a pub at 18 by yourself... So you sort of had to have a boyfriend in tow or a group of girls. 
As an 18-year-old woman, Jessica reminds us of how navigating pub entry does not function outside of structuralist relations of power. Jessica alerts us to Probyn’s (2003) argument of how historical weight of ideas layered over Australian pubs helps naturalise the presence of single men socialising together, while restricting access of lone young single women. As consistent with the work of Donkersloot (2012), Jessica illustrates how women navigate the moral sentiment they may provoke entering a pub alone by organising entry with 'a group of girls' or 'boyfriend'.

As a farmer's wife, Jessica found herself living with a partner who drank regularly at home. However, Jessica never questioned her husband's drinking. Instead, in a place which privileges materially and discursively men drinking as the norm, Jessica described how drinking beer was naturalised as a gendered activity at home.

Jessica: ... my husband would usually have a beer, not every night but most. Just one or two stubbies, and if his friends came over they would have quite a few drinks and 'cause he was local he grew up here, and it think it's one of those things they do; they drink a lot here...

As 'locals’ and breadwinners, Jessica understood excessive drinking as a normative homemaking practice for farming men. Regardless of cohort generation, there were many similar accounts of married farming women who communicated that drinking in the home felt 'good' in relation to their husbands, to both reduce their stress and sustain friendship networks. Echoing the work of Leyshon (2008), drunkenness is naturalised as important for socialising and a means of building gender difference. Farming women, like Jessica, overlook medicalised risks and instead sanctioned her husband to 'have quite a few drinks' as one way of being supportive.

As a mother, home drinking was also regarded by Jessica as a practice of care for her sons. For example, Jessica laughed when recounting the horror expressed by her mother 
when she would fill empty beer (stubby) cans up with water for her sons at meal times to mirror her husband’s drinking practice.

Jessica: I remember my mother being horrified because we had empty stubbies that we filled with water, just when we set the table for dinner. The kids were only four, six, and eight or something, and they got an empty stubby of water. 'Cause it was a way of getting water into them, 'cause they were being cool like Dad, you see. But Mum was horrified, ha ha. I said 'it's just water Mum, they know it's water. It's just to get them to drink it.'

Jessica's narrative depicts generational change in regards to the introduction of alcohol at a young age within a familial context. Jessica narrative is illustrative of Valentine et al.'s (2008) discussion of the shift in parenting techniques that forge familial relationships from the parent as authoritative figure that banned alcohol as a threat to family life, to that of the friend and supplier. Jessica’s laughter conveys her mother’s nonconformity to filling empty beer cans with water as a drinking vessel for children. Following Ahmed (2004), Jessica's mother's horror may be read as a distancing response. The beer cans filled with water may have been intensely felt by Jessica's mother as a threat not only to herself as a grandmother but to the home assemblage. Instead, for Jessica the narrative of the water-filled beer cans as a way to being 'cool', something that fathers do, allows her to associate herself with positive value, emotions and affect. Indeed, concerned with the wellbeing of her sons, the water-filled beer cans are about caring for her children and family.

Jessica went onto convey the taken-for-granted-ness of country town drinking cultures, the acceptance that her young teenage sons drink 'too much' and the positive value of her support for drinking in the family home.

Jessica: ... well my boys, I think my boys drink too much, and they're stupid when they do, and they do stupid things ... I think it’s [drinking to become drunk] one of those 
things they [young, single country men] do, they drink a lot up here... I'd rather have them out here and know where they were and safe than at someone else's house...

As a mother knowledgeable of the risks and concerned with the wellbeing of her sons, Jessica taps into wider discourses that position the home as a 'safe' place for underage drinking for young men (Jayne et al. 2011). Jessica protects the bodies of those she loves by not being against drinking like her own mother. To be against drinking can only be against maternal love and therefore cannot protect bodies from the excess of alcohol. Through the private house party, Jessica exercises a narrative of care as protection from the known and perceived risks of alcohol consumption. The affective capacity of care narrated through house parties illustrates Jessica’s allegiance to the ideal of the nuclear family, affirming her maternal qualities.

Jessica goes on to suggest another way that gender is configured through drinking: that proper country women 'settle' a man down from excessive drinking. This is tied to heterosexuality, sex and family.

Jessica: I think there’s definitely a, I think they [young men] drink too much, a lot of them. But I don’t think it’s anything new. You know, I don’t think it’s anything less than my 93-year-old grandfather who now hasn't had a drink for 50 years but I'm sure it's nothing he didn't do when he was young and then they grow out of it. But ummm, you know, mainly they get girlfriends and settle down.

Jessica takes as common sense that young single rural men 'drink too much'. At the same time, Jessica taps into narratives of drunkenness as a 'rite of passage' into adulthood for men (Crawford and Novak 2006; Valentine et al. 2008). Her narrative positions women as sensible drinkers by labelling the 'girlfriend' as the 'responsible' figure; an agent of governance, transformation and self-restraint (Lyons and Willot 2008). Animated by the love of women, the organisation and regularity norms to protect, care for and sustain valued lives 
within the ideal heterosexual family home suggests another expression of surveillance by which the relationship between gender an alcohol is reconfigured.

\section{Socialising bodies}

Our third vignette illustrates how the techniques that govern gender norms and affective forces are reconfigured through the lived experiences of 'mature' socialising bodies (i.e. women over the age of 60). Penny is 68 years of age and her drinking experiences are shaped by community hall dances, marriage, childcare and intermittent farm work. Unlike Kayla and Jessica, Penny in Bellevue recalled no parental rules around drinking, nor peer pressure to drink while growing up in the 1960s on a dairy farm. Furthermore, pubs were narrated as secondary to community halls as social spaces for her generation.

Penny: We'd go to the football dances once a week. We'd go to the football and then to the dances afterwards. Every town had one in their little hall. The pub scene wasn't as big as it was now, and well, so you didn’t need to go to the pub. This was in the Sixties ... Drinking: we never worried about it. It [drunkenness] didn't happen as much then. There wasn't the large drinking culture. [I] might have had a drink a couple of times, but it was never an issue, as drink[ing] was not something that was done very much.

Today, Penny’s drinking patterns and preferences are shaped by the rhythms, routines, roles and responsibilities of domestic life as a farmer's wife, which reinforce gendered dualisms. Like Jessica, Penny understood the roles and responsibilities of being and becoming wives as providing support to farming men. As Bryant (2013) argues, this supportive role often required women reducing the stress on men by taking on the majority of domestic tasks and increasing their participation in the sphere of farming. For example, Penny spoke of how she negotiated the traditional gendered scripts and spatial norms associated with farming and marriage. 
Penny: My husband, in those days, he would have been a bit put out [if I continued to work], being able to provide for me, this was in the sixties ... I was very happy to stay at home while the children were small. And then when they became teenagers it wasn't enough for me to be hanging washing on the line, you know. Handling cattle in the stockyard was too big a challenge. So, I went back to the solicitors ... [for] another 10 years ... Then I threw myself into farming with my husband. I did lots of courses. He's very focused and dedicated to the land. ... So, now we do speak the same language. And he does ask my opinion on things. I feel I have reasonable input. I really would rather be outside than doing housework. I do help, if my husband asks for help.

Penny points to the well-documented gendered norms of paid and unpaid work associated with heterosexual marriage and the birth of children in the 1960s (Bryant and Pini 2011). Equally, Penny reveals how gender inequalities are reproduced through understandings of the physicality of farm work, machinery and livestock (Pini 2008). For example, Penny deemed the physical labour of handling cattle 'too big a challenge'. What is important to note is how agricultural courses enabled Penny to be supportive but only when asked. Penny understands the farming decisions are tied to her husband's masculinity as provider. Today, Penny's drinking patterns and preferences are shaped by the rhythms, routines, roles and responsibilities of domestic life as a farmer's wife that reinforce gendered dualisms. Penny spoke of domestic drinking as a daily reward and remedy for farming work:

Penny: Summers tend to wear me out with daylight savings ... you know we end up milking about nine o'clock or something and I keep telling him [her husband] I'm too old for this... most nights. ... [we] usually have a red wine. I quite like a medium dry sherry if it's really cold ... in summer, we'll have a beer.

As argued by Waitt and De Jong (2014), the bodily sensations of alcohol help to assemble and reassemble the temporalities and spatialities of everyday life. Penny conveyed drinking with their evening meal each night at least one glass of wine in winter, and beer in summer as a tonic for farm work. Penny goes onto explain how alcohol is integral to constituting the weekend. 
Penny: ... he [Penny's husband] and I go there [the Bellevue Hotel/Motel] to get some nice meals and we go there sometimes on our own, sometimes with friends. We usually try to get out on weekends, most weekends otherwise we would stay home all the time. When we stay home we usually deal with business matters... We're not big drinkers. We don’t really drink a lot. We might usually have only one or two glasses. We can always drive home. I don't like feeling out of control; feeling like, no, [pause], I’ve had enough. No, we're social drinkers really.

For Penny, the significance of going out to a hybrid bar-restaurant takes on particular significance since the boundaries between 'home' and 'work' are blurred by the long working hours of everyday farm life. Like Kayla, Penny underscores the importance of the affective elements of drinking practices in maintaining the sociability of friendship circles. And, like Kayla, the way that Penny integrates herself into weekend cultures is bound up with classed, aged and gendered identities and moralities. However, unlike Kayla, Penny’s words illustrate conformity to middle-class feminine imperatives of sobriety and demeanour (Skeggs 2002). In Penny’s words, ‘I don’t like feeling out of control'. Penny illustrates how alcohol is embedded into bodily habits which 'respectable country women' typically take for granted to help make sense of time and place. Penny pursues these 'responsible’ drinking practices in order to produce the desired experience of self-care through socialisation and relaxing. However, Penny’s practices may not necessarily match health recommendations that advise two to three alcohol-free days a week to enable liver recovery (NHMRC 2011). As Jayne et al. (2012) argue, the health recommendations surrounding alcohol consumption do not always match what the assemblage of the body knows and feels to be 'acceptable drinking'. Finally, Penny's narrative provides clues as to the emergence of new form of public culture in cafés and hybrid bar-restaurants, which are catalytic in changing how mature-age women inhabit this country town. The new commercial hospitality spaces have not gentrified Bellevue along the lines of a middle-class ‘domestication by cappuccino’ (Atkinson 2003), but these sit alongside conventional male-orientated venues. Penny provides insights into 
how one group of mature-age women make use of these new hospitality spaces in their everyday lives in an informal and convivial way.

Penny: We go out for lunch roughly once a month, actually there are nine in the group, but usually someone is missing, visiting relatives or something, but yes, it's a nice group. We look forward to our little outings. ... The upmarket place in town, the wine bar. Yes... it's got interesting food. We have a glass of wine and a chat... we provide a time and space for sharing problems, we air our little problems. Do a bit of group problem solving and things, and it's not all doom and gloom... most of the time. We just update and keep each other buoyed up if we need to... Very enjoyable.

Crucially, what is happening here is more than the aesthetics of consumption. This meeting place also sustains a new public sociality, collective and solidarity among these mature-age women. The taste of the food, the atmosphere of the cafés and restaurants, as well as the alcohol content of the wine allows them to relax and territorialise a space of support and sociability. This space allows opportunities for these women to share anxieties, fears and grief, as well as love, hope and joy. Alongside gardening tips are possibilities to support women living with cancer, dementia and other illnesses. The emergence of the hybrid barrestaurant in Bellevue allowed the emergence of a public midday food and drinking-based social culture among mature age women that was previously uncommon in Bellevue. For Penny and her friends, the affective elements of alcohol are integral to the mix of things and people that help sustain the experience of life in Bellevue as 'enjoyable'.

\section{Conclusion}

To advance a more nuanced understanding of gendered drinking meanings and patterns we present a conceptual framework that explores how the biopower of drinking and bodily drinking habits are maintained and challenged by an assemblage of embodied somatic practices. The gendered spatial patterns and health inequalities related to drinking ought not to be reduced to pre-existing categories of gender and place. For all the discussion of 
gendered drinking that goes with the moral panic of alcohol-fuelled violence, alcohol consumption is not determined by gender, although the two are intertwined. We cannot understand the gendered dimensions of drinking that appear in public health reports without appreciating how bodies that consume alcohol are simultaneously 'object-targets of' and ‘conditions for’ making everyday geographies.

We have shown through the use of vignettes how gendered bodies and alcohol drinking practices in the constellations of relationships that comprise a country town are expressed through various forms of biopower - such as; pregnancy, mothering, partnering and socialising. Consuming alcohol may produce guilt in relation to bodies, spaces and ideas about 'good' mothering. Conversely, we have drawn attention to the somatic pleasures of becoming a 'good' farmer's wife and mother through supplying alcohol to husbands and teenage sons, which transcend medicalised risks. Moreover, we identified the particular value of alcohol for certain projects of self-care, concerned with both making times and places for socialisation more acute or satisfyingly rich, and in turn reworking gendered power relations encoded and sustained on bodies. For these women, units of alcohol are too narrowly instrumental and calculative in everyday contexts stitched into the gendered relations of care and support in considering how much alcohol is ‘too much' or 'too little'. Like Jayne et al. (2012), our research challenges 'units' as the dominant means of measuring drunkenness and medical risk.

Future alcohol research may benefit from conceiving gender as a material and expressive force produced in particular assemblages comprising a variety of practices and animated by experiences. To better understand alcohol-related pleasures and risks, we encourage others to explore how gender is lived in and through bodies by paying closer attention to how the 'right' consumption choices are part of a drinking assemblage. In this sense, we emphasise how the body is shaped by hierarchies of power and is an instrument to 
maintain power. But just as hierarchies of power relations circulate and maintain repressive subjectivities that are sustained in our bodies, some experiences of alcohol-related pleasure in particular contexts are so powerful they challenge the ideologies entrenched in our bodies. Alternative types of harm minimisation strategies can benefit from including the varying ways in which the experience of risk is mediated by how the gendered subject emerges within drinking assemblages as an 'object-target of' and 'condition for' contemporary forms of biopower.

\section{Acknowledgements}

Thank you to all the women who participated - sharing their narratives and experiences of alcohol. We thank the three anonymous reviewers and the journal editor for their helpful commentaries, each of which served to strength our argument.

\section{Notes on contributors}

Gordon Waitt is Professor of Human Geography at the University of Wollongong. He has contributed feminist perspectives to geography and leisure and tourism studies. He recently co-authored Tourism and Australian Beach Cultures: Revealing Bodies (Channel View Publications). In 2006, with Kevin Markwell, he co-authored Gay Tourism: Culture and Context (Haworth Publications).

Susannah Clement is a PhD Candidate at the University of Wollongong. Her research interests include alcohol geography, feminist geography, urban walking and children's mobility. Her current $\mathrm{PhD}$ project explores pedestrian practices in the regional city through recording the narratives and experiences of walking together with parents and children.

\section{References}

Ahmed, S., 2004. The Cultural Politics of Emotion, Edinburgh: Edinburgh University Press and Routledge.

Atkinson, R., 2003. Domestication by cappuccino or a revenge on urban space? Control and empowerment in the management of public spaces. Urban Studies, 40, pp.1829-1843.

Australian Bureau of Statistics, 2012. 2011 Census of Population and Housing Community Profiles, Canberra: Australian Bureau of Statistics. 
Australian Institute of Health and Welfare, 2011. 2010 National Drug Strategy Household Survey report, cat: PHE 145, Canberra: Australian Institute of Health and Welfare.

Bøhling, F., 2015. Alcoholic assemblages: Exploring fluid subjects in the night-time economy. Geoforum, 58, pp.132-142.

Bryant, L., 2013. Heterosexual marriage, intimacy in farming. In A. Gormany-Murray, B. Pini, and L. Brynat, eds. Sexuality, Rurality and Geography. Lanham: Lexington Books, pp. 51-66.

Bryant, L. and Pini, B., 2011. Gender and Rurality, New York: Routledge.

Connell, R., 1987. Gender and Power: Society, the Person and Sexual Politics, Cambridge: Policy Press.

Crawford, L.A. and Novak, K.B., 2006. Alcohol abuse as a rite of passage: The effect of beliefs about alcohol and the college experience on undergraduates' drinking behaviours. Journal of Drug Education, 36(3), pp.193-212.

Day, K., Gough, B. and McFadden, M., 2004. 'Warning! Alcohol can seriously damage your feminine health’. Feminist Media Studies, 4(2), pp.165-183.

Donkersloot, R. 2012. Gendered and generational experiences of place and power in the rural Irish landscape, Gender, Place and Culture, 19(5), pp. 578-599.

Ettore, E., 1997. Women and Alcohol: A private Pleasure or a Public Problem?, London: The Women's Press.

Foucault, M. 1978. The History of Sexuality: An Introduction, Vol. 1., London: Penguin. Fox, N., 2012. The body, Cambridge: Polity Press

Fox, R., Heffernan, K. and Nicolson, P. (2009) 'I don’t think it was such an issue back then', changing experiences of pregnancy across two generations of women in south-east England, Gender, Place and Culture, 16(5), pp. 553-568.

Griffin, C., Bengry-Howell, A., Hackley, C., Mistral, W., and Szmigin, I., 2009. 'Every Time I Do It I Absolutely Annihilate Myself': Loss of (Self-)Consciousness and Loss of Memory in Young People’s Drinking Narratives. Sociology, 43, pp.457-476.

Grosz, E., 1994. Volatile bodies: toward a corporeal feminism, Bloomington: Indiana University Press.

Jackson, C. and Tinkler, P., 2007. 'Ladettes' and 'Modern Girls': ‘Troublesome’ young femininities. Review Literature and Arts of the Americas, 2(2), pp.251-272.

Jayne, M., Holloway, S.L. and Valentine, G., 2006. Drunk and disorderly: alcohol, urban life and public space. Progress in Human Geography, 30(4), pp.451-468. 
Jayne, M., Holloway, S.L. and Valentine, G., 2012. What Use Are Units? Critical Geographies of Alcohol Policy. Antipode, 44(3), pp.828-846.

Jayne, M., Valentine, G. and Holloway, S.L., 2010. Emotional, embodied and affective geographies of alcohol, drinking and drunkenness. Transactions of the Institute of British Geographers, 35(4), pp.540-554.

Jayne, M., Valentine, G. and Holloway, S.L, 2011. Alcohol drinking and drunkenness: (dis)orderly spaces, Burlington: Ashgate.

Jayne, M., and Valentine, G., 2014. Alcohol-related violence and disorder: New critical perspectives. Progress in Human Geography, pp.1-21

Leyshon, M., 2008. 'We're stuck in the corner': Young women, embodiment and drinking in the countryside. Drugs: Education, Prevention and Policy, 15(3), pp.267-289.

Liquor Accord, 2012. Liquor Accord Victoria. Available at: http://www.liquoraccord.org/liquor-accords/vic [Accessed October 6, 2014]

Longhurst, R., 2008. Maternities: gender, bodies and space, New York: Routledge.

Longhurst, R., Hodgetts, D. and Stolte, O., 2012. Placing guilt and shame: lone mothers’ experiences of higher education in Aotearoa New Zealand. Social and Cultural Geography, 13(3), pp.295-312.

Lyons, A., and Willot, S., 2008. Alcohol Consumption, Gender Identities and Women’s Changing Social Positions. Sex Roles, 59(9-10), pp.694-712.

MacLean, S., and Moore, D. 2014. 'Hyped up’: assemblages of alcohol, excitement and violence for outer-suburban young adults in the inner-city at night. The International journal on drug policy, 25(3), pp.378-85

McRobbie, A., 2009. The aftermath of feminism, London: Sage.

Miller, P.G. Coomber, K. Staiger, P. Zinkiewicz, L. and Toumbourou, J. W., 2010. Review of rural and regional alcohol research in Australia. The Australian Journal of Rural Health, 18(3), pp.110-117.

National Health and Medical Research Council, 2011. Alcohol guidelines: reducing the health risks. Available at: http://www.nhmrc.gov.au/your-health/alcohol-guidelines

Pini, B., 2008. Masculinities and management in agricultural organisation worldwide, Aldershot: Ashgate.

Probyn, E., 1996. Outside belongings, New York: Routledge.

Probyn, E., 2003. The Spatial Imperative of Subjectivity. In K. Anderson, ed. Handbook of Cultural Geography. London: SAGE Publications, pp. 290-299.

Probyn, E., 2005, Blush: faces of shame. Minneapolis: University of Minnesota Press. 
Race, K., 2009. Pleasure consuming medicine: the queer politics of drugs, Durham NC: Duke University Press.

Shaw, R., 2014. Beyond night-time economy: Affective atmospheres of the urban night. Geoforum, 51, pp.87-95

Skeggs, B., 2002. Formations of class and gender: becoming respectable, London: SAGE Publications.

Sweeney, B., 2014. To sexually perform or protect: masculine identity construction and perceptions of women's sexuality on a university campus in the Midwestern USA, Gender, Place and Culture, 21(9), pp. 1108-1124.

Tan, Q. H., 2013. Flirtatious geographies: clubs as space for the performance of affective heterosexualities, Gender, Place and Culture, 20(6), pp. 718-736

Tomkins, S., Sedgwick, E.K. and Frank, A., 1995. Shame and its sisters: a Silvan Tomkins reader, Durham: Duke University Press.

Valentine, G. Holloway, S.L. Knell, C. and Jayne, M., 2008. Drinking places: Young people and cultures of alcohol consumption in rural environments. Journal of Rural Studies, 24(1), pp.28-40.

van Campenhoot, G. and van Hoven, B. 2014. 'It's where blokes can be blokes': making places in a New Zealand rugby club, Gender, Place and Culture, 21(9), pp. 10901107.

Waitt, G, Jessop, L. and Gorman-Murray, A., 2011. 'The guys in there just expect to be laid': embodied and gendered socio- spatial practices of a 'night out' in Wollongong, Australia. Gender, Place and Culture, 18(2), pp.255-275.

Waitt, G. and De Jong, A., 2014. Embodied geographies of alcohol and the weekend in the Bega Valley, New South Wales, Australia. Leisure Studies, 33(2), pp.116-132.

Waterson, J., 1996. Gender divisions and drinking problems. In L. Harrison, ed. Alcohol problems in the community. London: Psychology Press, pp. 170-199.

Wilton, R. and Moreno, C.M., 2012. Critical geographies of drugs and alcohol. Social and Cultural Geography, 13(2), pp.99 - 108. 